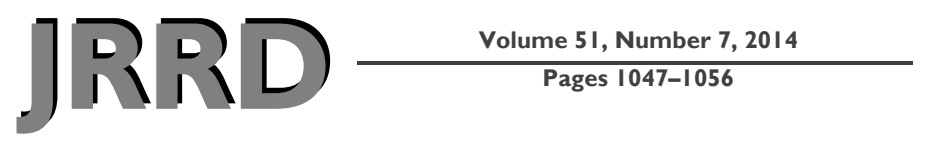

\title{
Effects of hyperbaric oxygen on eye tracking abnormalities in males after mild traumatic brain injury
}

\author{
David X. Cifu, MD; ${ }^{1-2}$ Kathy W. Hoke, PhD; ${ }^{3}$ Paul A. Wetzel, PhD; ${ }^{4}$ Joanna R. Wares, PhD; ${ }^{3}$ George Gitchel, \\ MS; ${ }^{4}$ William Carne, PhD $^{\mathbf{1}^{*}}$ \\ ${ }^{1}$ Department of Physical Medicine and Rehabilitation, Virginia Commonwealth University, Richmond, VA; ${ }^{2}$ Physical \\ Medicine and Rehabilitation Program Office, Department of Veterans Affairs, Richmond, VA; ${ }^{3}$ Department of Mathe- \\ matics and Computer Science, University of Richmond, Richmond, VA; ${ }^{4}$ Department of Biomedical Engineering, Vir- \\ ginia Commonwealth University, Richmond, VA
}

\begin{abstract}
The effects of hyperbaric oxygen $\left(\mathrm{HBO}_{2}\right)$ on eye movement abnormalities in 60 military servicemembers with at least one mild traumatic brain injury (mTBI) from combat were examined in a single-center, randomized, double-blind, sham-controlled, prospective study at the Naval Medicine Operational Training Center. During the 10 wk of the study, each subject was delivered a series of 40 , once a day, hyperbaric chamber compressions at a pressure of 2.0 atmospheres absolute (ATA). At each session, subjects breathed one of three preassigned oxygen fractions $(10.5 \%, 75 \%$, or $100 \%)$ for $1 \mathrm{~h}$, resulting in an oxygen exposure equivalent to breathing either surface air, $100 \%$ oxygen at 1.5 ATA, or $100 \%$ oxygen at 2.0 ATA, respectively. Using a standardized, validated, computerized eye tracking protocol, fixation, saccades, and smooth pursuit eye movements were measured just prior to intervention and immediately postintervention. Between- and within-groups testing of pre- and postintervention means revealed no significant differences on eye movement abnormalities and no significant main effect for $\mathrm{HBO}_{2}$ at either 1.5 ATA or 2.0 ATA equivalent compared with the sham-control. This study demonstrated that neither 1.5 nor 2.0 ATA equivalent $\mathrm{HBO}_{2}$ had an effect on postconcussive eye movement abnormalities after mTBI when compared with a sham-control.
\end{abstract}

Key words: blast injury, blinded, concussion, eye tracking, hyperbaric oxygen, postconcussive syndrome, randomized, saccades, sham controlled, traumatic brain injury.

\section{INTRODUCTION}

As a result of the significant numbers of Veterans and servicemembers (SMs) who sustained mild traumatic brain injuries (mTBI) from the Gulf wars, the U.S. Department of Veterans Affairs (VA) and Department of Defense (DoD) established integrated systems of care [12]. Through 2011, nearly 1 in 10 Veterans who served in Operation Enduring Freedom and Operation Iraqi Freedom and enrolled in the VA were diagnosed with at least one deployment-related mTBI [3]. Of these individuals,

Abbreviations: ANOVA $=$ analysis of variance, ATA $=$ atmospheres absolute, DoD = Department of Defense, $\mathrm{HBO}_{2}=$ hyperbaric oxygen, $\mathrm{mTBI}=$ mild traumatic brain injury, NMOTC $=$ Naval Medicine Operational Training Center, PPCS $=$ persistent postconcussive syndrome, $\mathrm{RPQ}=$ Rivermead Post-Concussion Questionnaire, SD = standard deviation, $\mathrm{SM}=$ servicemember, $\mathrm{SPEM}=$ smooth pursuit eye movement, TBI = traumatic brain injury, VA = Department of Veterans Affairs.

*Address all correspondence to William Carne, PhD; Department of PM\&R, Virginia Commonwealth University, 1223 East Marshall Street, Richmond, VA 23298; 804828-4231; fax: 804-828-6755. Email: lasile@aol.com http://dx.doi.org/10.1682/JRRD.2014.01.0013 
more than 90 percent were also diagnosed with at least one additional condition (e.g., posttraumatic stress disorder or pain) that likely complicated both the clinical presentation and subsequent treatment [3-4], a finding that has been labeled Postdeployment Syndrome [5] and may help explain the higher rate of persistent postconcussive syndrome (PPCS) in military personnel than civilian individuals [3]. Moreover, the high incidence of repeated exposures to blast, with potential for cumulative brain injury, may also contribute to prolongation of recovery and difficulty in symptom attribution [6-7]. The persistence of often disabling symptoms in a high proportion of returning SMs and Veterans has prompted the use of a significant number of alternative treatment strategies, including meditation, acupuncture, tai chi, continuum movement therapy, and hyperbaric oxygen $\left(\mathrm{HBO}_{2}\right)$ [3-8].

$\mathrm{HBO}_{2}$ has been advocated for the acute treatment of carbon monoxide poisoning, burns, crush injuries, and air embolism; the chronic management of pressure ulcers, gangrene, radiation necrosis, brain abscess, anemia, osteomyelitis, and retinal artery blockage; and to improve the long-term effects of ischemic stroke, autism, and cerebral palsy [9]. However, investigations evaluating the effect of $\mathrm{HBO}_{2}$ on subjective measures of PPCS have not demonstrated clinically meaningful improvement $[8,10$ 12]. In contrast to this lack of efficacy in subjective measures of brain dysfunction, there are many basic science studies supporting the effects of $\mathrm{HBO}_{2}$ on objective findings of brain recovery in animals [13]. For example, in brain-injured rodents, $\mathrm{HBO}_{2}$ promotes mitochondrial recovery and decreases apoptosis in hypoxic nerve cells, which is associated with cognitive recovery and a reduction in hippocampal neuronal cell loss [13-15]. The purported mechanisms of $\mathrm{HBO}_{2}$ on brain injury include enhanced neural stem cell activation and growth, reduced hypoxic-induced myelin damage, elevated cellular ATP (adenosine triphosphate) levels, and upregulated HIF-1 (hypoxis-inducible factor-1) alpha-enhancing neuronal tolerance to hypoxia [16-19]. Based on these positive findings of $\mathrm{HBO}_{2}$ in animal models, we hypothesized that objective measures of clinical brain function and recovery would demonstrate improvements. To test this hypothesis, we identified the central visual pathways as an objective and readily accessible indicator of brain health. Eye tracking, which measures the integrity of these pathways, has been demonstrated as a user-friendly, low-cost, noninvasive marker of individuals with mTBI [20-24].
Common assessments of eye tracking include the measurement of saccades, smooth pursuit eye movement (SPEM), and fixation [23-24]. Saccades, the simultaneous movements of both eyes in the same direction allowing for fixation of the image on the fovea, are likely to be affected by even mild brain injuries because they involve the concerted interactions of multiple and diverse areas of the brain [23]. Additionally, the various components of saccades are largely free of cognitive influence and not interdependent. SPEM has been examined in the traumatic brain injury (TBI) population and, although believed to be a potential component of the difficult to identify and diagnose visual complaints seen with mTBI, research has produced equivocal results [24]. Data involving fixation, defined as maintaining a foveal image, in individuals with TBI have not been well studied, in part due to technical difficulties in measurement; however, advances in both technology and data processing have overcome this.

Investigation of these movement parameters demonstrated differences between SPEM and saccades in individuals with PPCS and injury-free controls [20]. These differences were noted in horizontal and vertical stepwise target displacement task responses between individuals with symptomatic mTBI and controls. Subjects with symptomatic mTBI had smaller predicted peak velocities, longer durations, larger position errors, and smaller saccadic amplitudes. These symptomatic subjects also had amplitudes that were significantly larger for the horizontal smooth pursuit task, were more likely to respond with smaller primary saccades to step changes in target position, less accurately tracked the stepwise moving targets, and had lower pursuit gain than controls [20]. No between-group differences were noted for fixation measures.

For this investigation of the effects of $\mathrm{HBO}_{2}$ on mTBI-related symptoms, we hypothesized that there would be significant differences in postcompression SPEM and saccadic eye movements between the sham and intervention groups.

\section{METHODS}

This study was a sham-controlled, blinded, randomized, three-arm trial of $\mathrm{HBO}_{2}$ exposure on combat-related, symptomatic mTBI that was begun in 2009 at the Naval Medicine Operational Training Center (NMOTC) at Naval Air Station Pensacola. Other outcome measures 
from this trial have been reported [11-12]. This study received appropriate governmental and institutional review board approvals. Sixty-one Active Duty military SMs with PPCS were recruited from U.S. military bases. Inclusion criteria included confirmed diagnosis of mTBI by a TBI specialist, postconcussive symptoms for at least 3 mo, injury occurrence within 3 yr, at least 2 mo stable psychiatric status, and no change in psychotropic medications for at least 1 mo. The study physiatrist confirmed a diagnosis of TBI based on history, physical examination, and a review of all the medical records of the subjects, including any available battlefield information, from the time of the traumatic event to the present. Exclusion criteria included any contraindication to hyperbaric exposure, previous exposure to $\mathrm{HBO}_{2}$, or inability to undergo testing (e.g., superimposed ophthalmic conditions such as ocular injury and strabismus). All subjects were questioned as to whether they had any double vision, blurred vision, or floaters. Demographics; clinical information; and physical, cognitive, and measures of behavioral functioning were obtained.

After baseline testing, all subjects were relocated to NMOTC for 2 mo to undergo the hyperbaric chamber exposures. The hyperbaric chamber exposures, which approximate the community standard of care and meet all safety guidelines [8-9], have been described in prior publications from this research team [10-12].

\section{Statistical Analyses}

This article presents an analysis of the effects of the hyperbaric chamber exposures on eye tracking characteristics of the control and treatment group members by comparing baseline (time 1) measures to immediate postcompression (time 2), and 3 mo postcompression (time 3) results. Immediate postcompression outcome measurements were obtained within the first week following last exposure. Statistical measures of eye tracking were used to test for changes within and between subject groups at times 1, 2, and 3. Previous research has demonstrated the utility of these measures in distinguishing between mTBI and normal controls [20].

We analyzed multiple measures (see Figure) using a mixed-model analysis of variance (ANOVA), with time (times 1, 2, and 3) as the within-subjects factor and oxygen-level (groups A, B, and C) as the between-subjects factor. The studentized residuals were analyzed for outliers and normality. If there was only one outlier, the analysis was done with and without it. In the cases of multiple outliers or a large deviation from the assumption of nor-
SACCADIC PARAMETERS

Primary Position Error: the absolute value of the difference between the target displacement and the amplitude of the primary saccades.

Three submeasures of primary position error were calculated:

- Mean of the Normalized Position Error. The mean of the absolute value of the ratio between the position error and the target displacement. Normalization attempts to account for the dependency of the amplitude of the position error on the amplitude of the target displacement.

- Standard Deviation of the Ratio of the Position Error and the Target Displacement.

- Mean of the Absolute Value of the Non-normalized Position Errors.

Final Position Error: The absolute value of the difference between the target displacement and the position of the eye before the next target movement. The same three submeasures for primary position error were calculated for final position error.

Mean of the Absolute Value of the Normalized Primary Saccadic Amplitude: The mean of the absolute value of the ratio between the primary saccadic amplitude and the target displacement for all saccades per individual. Here, normalization attempts to account for the dependency of the amplitude of the primary saccades on the amplitude of the target displacement.

Predicted Velocity, Acceleration, Duration: Curves were fit to predict peak velocity, peak acceleration, and duration given the amplitude of the saccade for each individual for horizontal and vertical tracking tests.

- $1^{\circ}$. Predicted values of peak velocity, acceleration, and duration at for $1^{\circ}$ saccade.

- $5^{\circ}$. Predicted values of peak velocity, acceleration, and duration at for $5^{\circ}$ saccade.

SMOOTH PURSUIT PARAMETERS

Minimum Gain: The minimum of the ratios of eye velocity and target velocity between saccades.

Mean Absolute Normalized Saccadic Amplitude: The mean of the absolute value of the ratio of saccadic amplitude and target velocity. Normalization by target velocity attempts to account for dependency of saccadic amplitude on the velocity of the target.

Figure.

Measures for comparing saccadic and smooth pursuit data.

mality, we used nonparametric methods (Kruskal-Wallis for between-group analysis and Friedman two-way ANOVA by ranks for within-group). Levene's test was used to check homogeneity of variances and Box test was used to check the assumptions of covariances. Sphericity assumptions were also verified and, when violated, were corrected using the Greenhouse-Geisser correction.

When the interaction term was significant, the assumption of homogeneity of covariances was not met. In these cases, we used nonparametric tests and performed separate repeated-measures ANOVAs for each oxygen-level group, as well as separate one-way ANOVAs between oxygen-level groups at each time point.

\section{Eye Tracking Procedures}

The techniques used to obtain the pre- and posthyperbaric chamber exposure saccadic movement and SPEM 
have been described in prior publications from this research team [20].

\section{RESULTS}

One-hundred twenty-eight subjects met the initial study eligibility and consented for evaluation. Of the 128 candidates, 61 met the full study criteria and were randomly assigned into one of the three groups. Primary reasons for exclusion were active medication changes, schedule conflicts, and the inability to confirm the diagnosis of mTBI. One of the 61 study participants was unavailable for the immediate postintervention assessment. Less than 1 percent of all scheduled chamber sessions were postponed because of medical complaints and all were rescheduled per the protocol. All study subjects were male and had sustained at least one mTBI, with the most recent TBI occurring a mean of 8.5 mo (standard deviation [SD] = $6.58 \mathrm{mo}$, range $=3-39 \mathrm{mo}$ ) prior to the baseline assessments. The etiologies of mTBI included improvised explosive device blast (85.3\%), uncategorized blasts (10.0\%), rocket propelled grenades (3.0\%), and mortar attacks $(1.7 \%)$. Self-reported additional concussions (mean $=2.1, \mathrm{SD}=0.95$, range $=1-4$ ) prior to the most recent blast injury were reported by just over 25 percent of the subjects. Of the 60 subjects who completed all of the pre- and postcompression procedures, 21 were in the sham-control group, 18 were in the 1.5 atmospheres absolute (ATA) equivalent group, and 21 were in the 2.0 ATA equivalent group. There was no precompression between group differences on these variables, as previously reported [11-12].

The 60-subject final sample had a mean age of $23.2 \mathrm{yr}$ $(\mathrm{SD}=2.95)$. Forty-seven $(78.3 \%)$ were Caucasian, 10 (16.7\%) were Hispanic, 2 (3.3\%) were African American, and $1(1.7 \%)$ was Native American. Of the 60 subjects, 19 were married, 38 were single, and 3 were divorced. One-way ANOVA and chi-square analysis revealed no between-group differences on demographics. There were no clinician-recommended or self-reported alterations of psychotropic medications by any subjects during the study period.

The symptoms of the research cohort were characterized using the Rivermead Post-Concussion Questionnaire (RPQ) [25], and these results, which demonstrated no between-group differences before or after hyperbaric chamber compressions, have been previously reported
[11]. Specific to this analysis, no subjects reported any active difficulty with vision on the three vision-related RPQ items - blurred vision, light sensitivity, and double vision.

To determine if a treatment effect existed, analyses were conducted for the eye tracking variables that had been identified as abnormal in prior research [20]. These variables were compared for between- and within-group differences over the three time periods. At pretreatment, there were no significant differences between groups for eye movement variables, verifying the efficacy of randomization. At immediate and 3 mo postcompression, both between- and within-group differences were examined.

\section{Saccades}

Saccadic data from each group were compared from the horizontal and vertical target displacement tasks. Data from horizontal and vertical direction eye movements were analyzed for the horizontal and vertical target displacement tasks, respectively. For each subject, duration, peak velocity, saccadic amplitude, and peak acceleration for all saccades were fit to models for both horizontal and vertical displacement tasks using the nonlinear curve fitting toolbox in MATLAB (MathWorks; Natick, Massachusetts). For peak velocity and acceleration of saccades, exponential models were used, while for saccadic duration a power function model was used [26]. After curves were fit for each subject, the predicted duration, peak velocity, and peak acceleration from the models for both the $1^{\circ}$ and $5^{\circ}$ saccades were compared between and within groups. Other measures of saccadic accuracy known to differ between mTBI and normal controls were also compared (Figure) [20]. Measures analyzed were mean (normalized and non-normalized) of the absolute value and SD of the primary and final position errors.

\section{Horizontal Tracking}

All of the fit data (peak velocity at amplitudes 1 and 5, peak acceleration at amplitudes 1 and 5, and duration at amplitudes 1 and 5), the mean of the normalized primary position error, and the number of primary saccades for the horizontal tracking tasks met the assumptions needed for repeated measures ANOVA. For all measures, there was no statistically significant interaction $(\alpha=0.05$ level) between the oxygen-condition and time. The main effect of oxygen-level showed no statistically significant differences between groups, and there were no significant 
within-group differences over time. When a potential statistical trend was identified (the $p$-value was between 0.05 and 0.10 for the interaction term), we performed separate repeated measures ANOVAs for each oxygen-condition and found no significant differences. $p$-Values and partial eta-squared values are reported for each of the variables that met the assumptions for the mixed model ANOVA in the Table.

The mean of the normalized final position error, the mean of the non-normalized primary position error, and the SD of the normalized position error did not meet assumptions and so univariate nonparametric tests were performed. No significant differences between or within groups were found.

\section{Vertical Tracking}

All of the data for the vertical tracking tasks met the assumptions for parametric tests except for the mean and SD of the normalized primary position errors. The data for the mean of the normalized final error, predicted velocity at $1^{\circ}$ and $5^{\circ}$, predicted acceleration at $5^{\circ}$, and predicted duration at $1^{\circ}$ did not meet the assumption of equal covariance, and therefore separate repeated measures ANOVAs were performed for each oxygen level.

Each variable that met the assumptions was analyzed using a mixed-model ANOVA, with time (1, 2, and 3) as the within-subjects factor and oxygen level (groups A, B, and C) as the between-subjects factor. No significant interactions between time and oxygen level were found. The main effect of oxygen condition showed no statistically significant differences between groups, and there were no significant within-group differences over time.
Of those variables for whom separate repeated measures ANOVAs for each group were calculated, no significant between-group differences on the factor of oxygen level were found. Analyses of these measures within groups found a statistically significant effect (or trend) of time for two conditions: predicted velocity (51.25, 53.23, 49.30 \% $)$ and acceleration (2,982.98, 3,109.20, $2,835.02 \% \mathrm{~s}^{2}$ ) at both $1^{\circ}$ and predicted velocity (209.21, 216.37, $203.19 \%$ and acceleration (11,294.69, $11,792.24,10,934.80 \% \mathrm{~s}^{2}$ ) at $5^{\circ}$ amplitudes for group B. The difference was only statistically significant between times 2 and 3 and reflected a slowing (or worsening) in predicted values between times 2 and 3 . The clinical relevance of slowing in these two parameters is unclear. No other significant differences were found.

When nonparametric analyses were utilized, no significant between- or within-group results were found. $p$ Values and partial eta-squared values are reported for each of the variables that met the assumptions for the mixed-model ANOVA in the Table.

\section{Smooth Pursuit}

Data for the horizontal and vertical smooth pursuit eye movement tasks were analyzed. The minimum gain and mean absolute normalized saccadic amplitude for both pursuit tasks were analyzed. Only data for the minimum gain from the horizontal smooth pursuit task met the assumptions for parametric tests. No significant interaction was found between the oxygen-condition factor and time ( $p=0.36$, partial $\eta^{2}=0.047$ ). The main effect of oxygen condition also showed no statistically significant

Table.

Mixed-model analysis of variance results: tracking variables.

\begin{tabular}{|c|c|c|c|c|c|c|}
\hline \multirow[t]{2}{*}{ Tracking } & \multicolumn{2}{|c|}{$\begin{array}{c}\text { Interaction, Oxygen Level } \\
\text { and Time }\end{array}$} & \multicolumn{2}{|c|}{$\begin{array}{l}\text { (Between-Subjects) Main } \\
\text { Effect, Oxygen Level }\end{array}$} & \multicolumn{2}{|c|}{$\begin{array}{l}\text { (Within-Subjects) Main } \\
\text { Effect, Time }\end{array}$} \\
\hline & $p$-Value & Partial Eta ${ }^{2}$ & $p$-Value & Partial Eta ${ }^{2}$ & $p$-Value & Partial Eta ${ }^{2}$ \\
\hline \multicolumn{7}{|l|}{ Vertical } \\
\hline $\begin{array}{l}\text { Mean of Non-Normalized Primary Position } \\
\text { Error }\end{array}$ & 0.44 & 0.051 & 0.53 & 0.037 & 0.24 & 0.042 \\
\hline Number of Primary Saccades & 0.59 & 0.036 & 0.84 & 0.011 & 0.19 & 0.048 \\
\hline \multicolumn{7}{|l|}{ Horizontal } \\
\hline Mean of Normalized Primary Position Error & 0.68 & 0.028 & 0.92 & 0.004 & 0.66 & 0.010 \\
\hline Number of Primary Saccades & 0.58 & 0.035 & 0.66 & 0.020 & 0.35 & 0.026 \\
\hline Predicted Velocity, $1^{\circ}$ Amplitude & 0.09 & 0.103 & 0.74 & 0.015 & 0.89 & 0.002 \\
\hline Predicted Velocity, $5^{\circ}$ Amplitude & 0.07 & 0.109 & 0.81 & 0.011 & 0.96 & 0.000 \\
\hline Predicted Acceleration, $1^{\circ}$ Amplitude & 0.14 & 0.088 & 0.52 & 0.032 & 0.90 & 0.000 \\
\hline Predicted Acceleration $5^{\circ}$ Amplitude & 0.14 & 0.087 & 0.68 & 0.019 & 0.99 & 0.000 \\
\hline
\end{tabular}


Table.

Mixed-model analysis of variance results: tracking variables.

Predicted Duration, $1^{\circ}$ Amplitude $\quad 0.69$

Predicted Duration, $5^{\circ}$ Amplitude $\quad 0.24$

0.026

0.82

0.85

0.010

0.40

0.008

0.29

0.022

0.031

differences between groups ( $p=0.10 ; \eta^{2}=0.097$ ), and there were no significant within-group differences over time ( $\left.p=0.85, \eta^{2}=0.004\right)$. Nonparametric univariate tests (within- and between-group) were performed on the other three variables with no significant within- or between-group differences found.

\section{DISCUSSION}

This investigation presents injury-related eye tracking characteristics from a subanalysis of a DoD-VA collaborative trial studying the effects of $\mathrm{HBO}_{2}$ on PPCS. This represents the first examination utilizing objective eye tracking measurements to assess the potential effect of $\mathrm{HBO}_{2}$. In this study, there were no clinically significant between-group differences on any of the eye tracking variables following hyperbaric chamber compressions. While there were within-group differences on two of the saccade parameters for one of the oxygencondition groups, there were no clinical improvements seen in any of the $\mathrm{HBO}_{2}$ conditions. Interestingly, the changes seen between times 2 and 3 in this group B reflected saccadic slowing rather than improvements in eye functioning. The implications of this change are unclear but certainly cannot be interpreted as beneficial. There were no other statistically significant differences identified over the array of multiple eye movements studied.

The overall findings of this study were similar to findings utilizing other outcome measures in this study sample [11-12] and the initial DoD-VA study [10]. The lack of differences among the three experimental conditions on these objective eye tracking measures suggests the $\mathrm{HBO}_{2}$ exerted no treatment effects on the parameters studied. These findings are noteworthy because this study specifically utilized the typical treatment pressures advocated by hyperbaric clinicians [13,27-29].

Examinations of oculomotor abnormalities and reports of visual dysfunction after mTBI, most commonly using the saccadic eye movements and the RPQ as outcome measures, have demonstrated that they are most likely seen in the first week after injury, maximally recover in the initial 3 mo postinjury period and have continued recovery for the next 3 mo [21,30-31]. Heitger et al., in 2009, reported on 36 civilians who were within 6 mo of mTBI, and the mean RPQ score for light sensitivity was 1.42, 0.2 for double vision, and 0.78 for blurred vision, all of which indicated that none of these symptoms were more of a problem than prior to the injury [31]. These findings are consistent with our findings of no meaningful visual complaints on the RPQ.

\section{CONCLUSIONS}

This study has a number of inherent limitations, as previously described [11-12]. The small sample size limits the study's power. Generalizability may be limited by sex. Additionally, the high follow-up rate seen secondary to the paid travel and Active Duty status (i.e., they received additional duty orders to be on the base) may be atypical of nonmilitary populations. A number of factors common to most of the study participants may have an as yet undetermined effect on eye movements, including general combat exposure with associated posttraumatic stress, depression, anxiety, substance abuse, and pain, which all have been associated with deployment [3-4]. Future studies examining the effect of these comorbidities on eye tracking may be of interest. Better understanding of the influence of deployment and other possible variables seen with the subjects, such as time postinjury, severity of injury, repeated injury, and medication usage and adjustments, may allow for a greater refinement of treatment protocols. Diagnosing mTBI relies on participant self-report, which is sensitive to subjective patient interpretation, memory, social desirability, and other issues such as personality factors and willingness to reveal problems; thus, subjects who report mTBI from combat exposure may have characteristics that are not typical of all individuals.

This well-controlled study of $\mathrm{HBO}_{2}$ use in symptomatic subjects with chronic mTBI demonstrated no significant eye movement improvements at either 1.5 or 2.0 ATA equivalent over sham-control. Importantly, this investigation incorporated many features lacking in prior studies of $\mathrm{HBO}_{2}$ use, including randomization, blinding, objec- 
tive outcome measure, and control groups. This investigation does not support a therapeutic role for $\mathrm{HBO}_{2}$ for patients with persistent symptoms after mTBI. This investigation utilized computerized eye tracking to examine the possible effects of hyperbaric exposures on individuals with mTBI with PPCS. There were no clinically meaningful improvements associated with the exposure to the $\mathrm{HBO}_{2}$.

\section{ACKNOWLEDGMENTS}

\section{Author Contributions:}

Study concept and design: D. X. Cifu, P. A. Wetzel.

Acquisition of data: G. Gitchel.

Analysis and interpretation of data: J. R. Wares, K. W. Hoke, D. X. Cifu, P. A. Wetzel..

Drafting of manuscript: D. X. Cifu, W. Carne, K. W. Hoke, J. R. Wares, P. A. Wetzel.

Critical revision of manuscript for important intellectual content: D. X. Cifu, W. Carne.

Statistical analysis: K. W. Hoke, J. R. Wares.

Obtained funding: D. X. Cifu.

Administrative, technical, or material support: D. X. Cifu.

Study supervision: D. X. Cifu.

Financial Disclosures: The authors have declared that no competing interests exist.

Funding/Support: This material was based on work funded by the Air Force Medical Support Agency Medical Modernization Directorate and the 711th Human Performance Wing for the primary study, the U.S. Navy Bureau of Medicine and Surgery for contract funding temporary duty requirements, and the U.S. Army Medical Materiel Development Activity for end of study contract funding. Dr. Cifu's efforts were supported, in part, through a Defense Advanced Research Projects Agency grant (N66001-09-2-206) and a contract from the U.S. Army Medical Materiel Development Activity. Dr. Carne’s efforts were supported, in part, through contracts from the U.S. Army Medical Materiel Development Activity and the Defense and Veterans Brain Injury Center. This work was funded primarily by the U.S. Army Medical Research Acquisition Activity (award W81XWH-082-0178) with support from the Defense and Veterans Brain Injury Center. Following completion of the study, additional support came from the DoD and VA Chronic Effects of Neurotrauma Consortium (grant W81XWH-13-2-0095).

Institutional Review: This study received appropriate governmental and institutional review board approvals from the McGuire VA Medical Center Institutional Review Board.

Participant Follow-Up: The authors have no plans to notify the study subjects of the publication of this article because of a lack of contact information.

Disclaimer: The views expressed herein do not necessarily represent the views of the VA, DoD, or the U.S. Government.

\section{REFERENCES}

1. Cifu DX, McNamee S, Gater D, Walker WC, Ericksen J, Murphy D, Oliver M. The Polytrauma Rehabilitation System of Care programs at the Richmond Veterans Administration Medical Center. Crit Rev Phys Rehabil Med. 2009; 21(3-4):197-213. http://dx.doi.org/10.1615/CritRevPhysRehabilMed.v21.i3-4.10

2. Lew HL, Poole JH, Vanderploeg RD, Goodrich GL, Dekelboum S, Guillory SB, Sigford B, Cifu DX. Program development and defining characteristics of returning military in a VA Polytrauma Network Site. J Rehabil Res Dev. 2007; 44(7):1027-34. [PMID:18075959] http://dx.doi.org/10.1682/JRRD.2007.05.0073

3. Cifu DX, Taylor BC, Carne WF, Bidelspach D, Sayer NA, Scholten J, Campbell EH. Traumatic brain injury, posttraumatic stress disorder, and pain diagnoses in OIF/OEF/OND Veterans. J Rehabil Res Dev. 2013;50(9):1169-76.

[PMID:24458958] http://dx.doi.org/10.1682/JRRD.2013.01.0006

4. Taylor BC, Hagel EM, Carlson KF, Cifu DX, Cutting A, Bidelspach DE, Sayer NA. Prevalence and costs of cooccurring traumatic brain injury with and without psychiatric disturbance and pain among Afghanistan and Iraq War Veteran V.A. users. Med Care. 2012;50(4):342-46. [PMID:22228249] http://dx.doi.org/10.1097/MLR.0b013e318245a558

5. Cifu DX, Blake P. Overcoming post-deployment syndrome: A six-step mission to health. New York (NY): DemosHealth; 2011.

6. Walker RL, Clark ME, Sanders SH. The postdeployment multi-symptom disorder: An emerging syndrome in need of a new treatment paradigm. Psychol Serv. 2010;7(3): 136-47. http://dx.doi.org/10.1037/a0019684

7. Lange RT, Brickell TA, Ivins B, Vanderploeg R, French LM. Variable, not always persistent, postconcussion symptoms following mild TBI in U.S. military service members: A 5-year cross-sectional outcome study. J Neurotrauma. 2013;30(11):958-69. http://dx.doi.org/10.1089/neu.2012.2743

8. Weaver LK, Cifu D, Hart B, Wolf G, Miller S. Hyperbaric oxygen for post-concussion syndrome: Design of Department of Defense clinical trials. Undersea Hyperb Med. 2012;39(4):807-14. [PMID:22908837]

9. Gesell LB, editor. Hyperbaric oxygen therapy indications. The Hyperbaric Oxygen Therapy Committee Report. 12th ed. Durham (NC): Undersea and Hyperbaric Medical Society; 2008.

10. Wolf G, Cifu DX, Baugh L, Carne W, Profenna L. The effect of hyperbaric oxygen on symptoms following mild traumatic brain injury. J Neurotrauma. 2012;29(17):260612. http://dx.doi.org/10.1089/neu.2012.2549 
11. Cifu DX, Hart BB, West SL, Walker W, Carne W. The effect of hyperbaric oxygen on persistent postconcussion symptoms. J Head Trauma Rehabil. 2014;29(1):11-20. [PMID:24052094] http://dx.doi.org/10.1097/HTR.0b013e3182a6aaf0

12. Cifu DX, Walker WC, West SL, Hart BB, Franke LM, Sima A, Graham CW, Carne W. Hyperbaric oxygen for blastrelated postconcussion syndrome: Three-month outcomes. Ann Neurol. 2014;75(2):277-86. [PMID:24255008] http://dx.doi.org/10.1002/ana.24067

13. Rockswold SB, Rockswold GL, Defillo A. Hyperbaric oxygen in traumatic brain injury. Neurol Res. 2007;29(2): 162-72. [PMID:17439701] http://dx.doi.org/10.1179/016164107X181798

14. Palzur E, Zaaroor M, Vlodavsky E, Milman F, Soustiel JF. Neuroprotective effect of hyperbaric oxygen therapy in brain injury is mediated by preservation of mitochondrial membrane properties. Brain Res. 2008;1221:126-33. [PMID:18561900] http://dx.doi.org/10.1016/j.brainres.2008.04.078

15. Zhou Z, Daugherty WP, Sun D, Levasseur JE, Altememi N, Hamm RJ, Rockswold GL, Bullock MR. Protection of mitochondrial function and improvement in cognitive recovery in rats treated with hyperbaric oxygen following lateral fluid-percussion injury. J Neurosurg. 2007;106(4): 687-94. [PMID:17432723]

http://dx.doi.org/10.3171/jns.2007.106.4.687

16. Peng Z, Ren P, Kang Z, Du J, Lian Q, Liu Y, Zhang JH, Sun X. Up-regulated HIF-1alpha is involved in the hypoxic tolerance induced by hyperbaric oxygen preconditioning. Brain Res. 2008;1212:71-78. [PMID:18439571] http://dx.doi.org/10.1016/j.brainres.2008.03.027

17. Wang XL, Yang YJ, Xie M, Yu XH, Liu CT, Wang X. Proliferation of neural stem cells correlates with Wnt-3 protein in hypoxic-ischemic neonate rats after hyperbaric oxygen therapy. Neuroreport. 2007;18(16):1753-56. [PMID:17921881] http://dx.doi.org/10.1097/WNR.0b013e3282f0ec09

18. Wang XL, Zhao YS, Yang YJ, Xie M, Yu XH. Therapeutic window of hyperbaric oxygen therapy for hypoxic-ischemic brain damage in newborn rats. Brain Res. 2008;1222:87-94. [PMID:18582850] http://dx.doi.org/10.1016/j.brainres.2008.05.016

19. Yang YJ, Wang XL, Yu XH, Wang X, Xie M, Liu CT. Hyperbaric oxygen induces endogenous neural stem cells to proliferate and differentiate in hypoxic-ischemic brain damage in neonatal rats. Undersea Hyperb Med. 2008;35(2):113-29. [PMID:18500076]

20. Cifu DX, Wares JR, Hoke KW, Wetzel PA, Gitchel G, Carne W. Differential eye movements in mild traumatic brain injury versus normal controls. J Head Trauma Rehabil. 2014. Epub ahead of print. [PMID:24695263] http://dx.doi.org/10.1097/HTR.0000000000000036
21. Heitger MH, Jones RD, Anderson TJ. A new approach to predicting postconcussion syndrome after mild traumatic brain injury based upon eye movement function. Conf Proc IEEE Eng Med Biol Soc. 2008;2008:3570-73. [PMID:19163480]

22. Kraus MF, Little DM, Donnell AJ, Reilly JL, Simonian N, Sweeney JA. Oculomotor function in chronic traumatic brain injury. Cogn Behav Neurol. 2007;20(3):170-78. [PMID:17846516] http://dx.doi.org/10.1097/WNN.0b013e318142badb

23. Ramat S, Leigh RJ, Zee DS, Optican LM. What clinical disorders tell us about the neural control of saccadic eye movements. Brain. 2007;130(Pt 1):10-35.

http://dx.doi.org/10.1093/brain/awl309

[PMID:17121745]

24. Suh M, Kolster R, Sarkar R, McCandliss B, Ghajar J; Cognitive and Neurobiological Research Consortium. Deficits in predictive smooth pursuit after mild traumatic brain injury. Neurosci Lett. 2006;401(1-2):108-13.

[PMID:16554121] http://dx.doi.org/10.1016/j.neulet.2006.02.074

25. Eyres S, Carey A, Gilworth G, Neumann V, Tennant A. Construct validity and reliability of the Rivermead postconcussion symptoms questionnaire. Clin Rehabil. 2005; 19(8):878-87. [PMID:16323387] http://dx.doi.org/10.1191/0269215505cr905oa

26. Leigh RJ, Zee DS. The neurology of eye movements. 4th ed. New York (NY): Oxford University Press; 2006.

27. Harch PG. The dosage of hyperbaric oxygen in chronic brain injury. In: Joiner JT, editor. Proceedings of the 2nd International Symposium on Hyperbaric Oxygenation for Cerebral Palsy and the Brain-Injured Child. Flagstaff (AZ): Best Publishing Co; 2002.

28. Harch PG, Andrews SR, Fogarty EF, Amen D, Pezzullo JC, Lucarini J, Aubrey C, Taylor DV, Staab PK, Van Meter KW. A phase I study of low-pressure hyperbaric oxygen therapy for blast-induced post-concussion syndrome and post-traumatic stress disorder. J Neurotrauma. 2012;29(1): 168-85. [PMID:22026588]

http://dx.doi.org/10.1089/neu.2011.1895

29. Rockswold SB, Rockswold GL, Zaun DA, Zhang X, Cerra CE, Bergman TA, Liu J. A prospective, randomized clinical trial to compare the effect of hyperbaric to normobaric hyperoxia on cerebral metabolism, intracranial pressure, and oxygen toxicity in severe traumatic brain injury. J Neurosurg. 2010;112(5):1080-94. [PMID:19852540] http://dx.doi.org/10.3171/2009.7.JNS09363

30. Heitger, MH, Jones RD, Frampton CM, Ardagh MW, Anderson TJ. Recovery in the first year after mild head injury: Divergence of symptom status and self-perceived quality of life. J Rehabil Med. 2007;39(8):612-21.

[PMID:17896052]

http://dx.doi.org/10.2340/16501977-0100 
31. Heitger MH, Jones RD, Macleod AD, Snell DL, Frampton CM, Anderson TJ. Impaired eye movements in post-concussion syndrome indicate suboptimal brain function beyond the influence of depression, malingering or intellectual ability. Brain. 2009;132(Pt 10):2850-70. [PMID:19617197] http://dx.doi.org/10.1093/brain/awp181

Submitted for publication January 19, 2014. Accepted in revised form April 30, 2014.
This article and any supplementary material should be cited as follows:

Cifu DX, Hoke KW, Wetzel PA, Wares JR, Gitchel G, Carne W. Effects of hyperbaric oxygen on eye tracking abnormalities in males after mild traumatic brain injury. J Rehabil Res Dev. 2014;51(7):1047-56. http://dx.doi.org/10.1682/JRRD.2014.01.0013

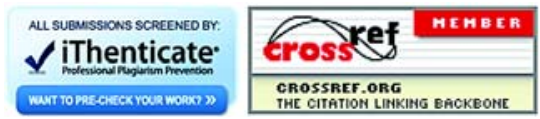


